\title{
Estratégias de mediação em situação de interação entre crianças em sala de aula
}

\author{
Veriana de Fátima Rodrigues Colaço \\ Eleonora Pereira \\ Francisco Edmar Pereira Neto \\ Hamilton Viana Chaves \\ Ticiana Santiago de Sá \\ Universidade Federal do Ceará
}

\begin{abstract}
Resumo
O presente artigo apresenta os resultados de uma pesquisa cujo objetivo era investigar as estratégias de mediação simbólica em situações de interação entre crianças em sala de aula, que possibilitam a construção de conhecimento compartilhado e de subjetividades. O estudo foi realizado em duas turmas de quarta série do ensino fundamental de uma escola particular da cidade de Fortaleza. Foram tomadas como unidade de análise as atividades discursivas de dois grupos de quatros crianças, quando realizavam conjuntamente tarefas escolares. A partir de um enfoque teórico-metodológico fundamentado na perspectiva histórico-cultural de Lev Vygotsky e na teoria da linguagem de Mikhail Bakhtin, os diálogos das crianças foram analisados, identificando-se estratégias de natureza semiótica que potencializam o aprendizado e a emergência de zona de desenvolvimento proximal nas situações de interação das crianças, ao mesmo tempo em que formas de comunicação e conduta eram forjadas no jogo de papéis que se constituíam nessas interações.
\end{abstract}

Palavras-chave: interação; mediação simbólica; zona de desenvolvimento proximal; construção de conhecimento; subjetividade

\begin{abstract}
Strategies of mediating children's interaction situations in classroom. The present paper has provided research results that aimed at investigating strategies symbolically mediating children's interaction situations in classroom enabling common knowledge and subjectivity construction. We have studied two primary school classes of the fourth year in a private school in Fortaleza, Ceará. We have analysed discursive activities of two four-child groups who worked together in learning tasks. We have focused on children's dialogues, identifying semiotic strategies enabling learning and proximal development zone emergence in children's interaction situations, all from a theoretical and methodological viewpoint based upon the historical and cultural perspective by Lev Vygotsky and the language theory by Mikhail Bakhtin, while communication and conduct practices were created in the game of roles that were formed in these interactions.
\end{abstract}

Keywords: interaction; symbolical mediation; proximal development zone; knowledge construction; subjectivity

$\mathrm{Q}$ uais seriam as possíveis estratégias de mediação empreendidas entre crianças em interação no contexto de sala de aula e como aquelas operam na sua construção de connecimento e de subjetividade? Estas foram as indagações centrais de nossa pesquisa, realizada por um grupo heterogêneo, composto por professora, estudantes e profissionais, cujo projeto está ligado ao Departamento de Psicologia da Universidade Federal do Ceará (UFC).

A pesquisa apresentada neste artigo resultou de uma parceria desenvolvida entre o Núcleo Cearense de Estudos e Pesquisas sobre a Criança (NUCEPEC), o Programa de Educação Tutorial do Curso de Psicologia (PET-Psicologia) e uma escola particular da cidade de Fortaleza que tem uma perspectiva construtivista e interacionista, envolvendo o acompanhamento de dois grupos de alunos de duas turmas de quarta série do Ensino Fundamental.

A proposta originou-se de estudos anteriores realizados com a temática dos processos de mediação nas interações infantis (Colaço, 2001; Colaço, 2004; Colaço, Mota, Chaves, Pereira, \& Sá, 2004), e teve como objetivo central a investigação, através de análise microgenética (Góes, 2000), de estratégias de mediação utilizadas por crianças em situação de interação no contexto escolar, quando participam de atividades escolares conjuntas voltadas à solução de problemas. A investigação pretendeu discutir o papel dessas interações nos processos de mediação social que implicam a construção de conhecimento compartilhado e processos de subjetivação. 
Compreendemos por estratégias de mediação o modo como as pessoas utilizam meios (instrumentais ou simbólicos) para intermediar suas atividades ${ }^{1}$, as quais envolvem interação com o outro e com o mundo. No caso específico da nossa pesquisa, isto implica a compreensão de que, ao realizarem de forma compartilhada as tarefas escolares, as crianças recorrem a meios que potencializam a sua comunicação com o outro, buscando formas de melhor entendimento e de efetivação das tarefas executadas. Nesta dinâmica, construções cognitivas são possíveis, assim como mobilização de afetos, motivações, condutas ou modos de interação, que se reorganizam num processo de singularização das pessoas envolvidas.

As bases teóricas que serviram de fundamento ao estudo encontram suporte na teoria histórico-cultural de Vygotsky sobre o desenvolvimento psicológico, compreendido como processo eminentemente social, e na teoria de Bakhtin, especialmente no seu pressuposto acerca da linguagem como processo enunciativo, dialógico e constitutivo da subjetividade.

A análise dos processos de desenvolvimento e aprendizagem à luz da teoria histórico-cultural ou sócio-histórica, expressão mais correntemente utilizada no contexto da Psicologia Social, tem possibilitado uma compreensão desses processos como mutuamente implicados e socialmente construídos. Nesta perspectiva, as situações de interação social assumem papel decisivo, pois são concebidas como um espaço simbólico gerador de conhecimentos, de apropriação de significados e de construção de subjetividades; por conseguinte, como promotoras de aprendizagens que impulsionam o desenvolvimento. Portanto, examinar os processos interacionais entre crianças significa buscar entender o fenômeno intersubjetivo, com suas implicações sobre o movimento dialético do desenvolvimento infantil, cuja constituição envolve processos interpsicológicos e intrapsicológicos (Colaço et al., 2004).

Ao tratar da temática da interação numa perspectiva histórico-cultural, é necessário esclarecer que esta não se restringe às relações sociais diretas ou face a face, mas também representa as interações com as ferramentas culturais (técnicas ou simbólicas), que se integram na atividade humana através da mediação social. No caso específico da nossa pesquisa, entretanto, privilegiamos as interações face a face, dado que o fio condutor de nossa investigação era o conhecimento construído de forma compartilhada. Assim, elegemos como unidade de análise a atividade discursiva (Coll \& Onrubia, 1998), representativa dos processos interacionais mediados semioticamente. Portanto, os conceitos de atividade discursiva, considerada como integração entre ação e linguagem; de interação social; e de construção compartilhada de conhecimento e de subjetividade ${ }^{2}$ foram norteadores deste estudo, tendo como bases referenciais, conforme mencionado acima, os aportes da teoria vygotskiana sobre desenvolvimento e aprendizagem e da teoria da linguagem de Bakhtin.

Vygotsky (1928/2001) nos ajuda a compreender o desenvolvimento em uma relação intrínseca com a aprendizagem, questionando pressupostos inatistas e ambientalistas correntes no início do século XX e que ainda encontram resquícios nas práticas pedagógicas atuais. Esse autor, inspirado no materialismo histórico dialético, rompe com propostas individualistas e universalizantes e apresenta uma concepção de desenvolvi- mento ancorada na compreensão do mesmo como decorrente do envolvimento da pessoa com o outro e com seu entorno, num processo de alterização e constituição mútua. Isso implica uma transformação dialógica do mundo e de si através de ricas mediações em diferentes contextos sócio-histórico-culturais, de intensas e múltiplas constituições em que desenvolvimento e aprendizagem entrelaçam-se, ganhando contornos e significados na cultura e na sociedade.

A proposta da teoria histórico-cultural, ao discutir a relação desenvolvimento-aprendizagem, aponta que a aprendizagem gera desenvolvimento, ou seja, o desenvolvimento é impulsionado pela aprendizagem. Neste sentido, aprender implica estar com o outro, que é mediador da cultura (Wertsch, Del Rio, \& Alvarez, 1998), e esta interação promove novas construções, ou seja, o desenvolvimento é um processo que ocorre interpsicologicamente, gerando construções intrapsicológicas. Dessa forma, diferencia-se das visões que pensam o desenvolvimento como um antecedente da aprendizagem ou como um processo já completado que a viabiliza.

Foi partindo destas discussões que Vygotsky introduziu o conceito de zona de desenvolvimento potencial ou proximal (ZDP). Apesar das críticas e limitações que podem ser feitas às noções iniciais dessa compreensão nos seus primeiros escritos de 1928, especificamente no livro Psicologia pedagógica (Vygotsky, 1928/2001), apresenta-se como uma perspectiva inovadora; principalmente para o contexto da época, constituindo-se como agregadora de vários elementos da teoria histórico-cultural ao ancorar-se numa proposta de desenvolvimento mediado, prospectivo, baseado em mudanças não apenas quantitativas, mas qualitativas.

O conceito de ZDP, no livro acima mencionado, é apresentado como a diferença entre os níveis de desenvolvimento real e potencial, sendo este ainda o entendimento de muitos teóricos atuais. Ao longo dos últimos anos e, a partir de leituras dos textos finais do autor, especialmente do texto "Pensamento e linguagem" (Vygotsky, 1934/1993), essa visão foi encontrando diferentes compreensões por parte de seguidores de sua teoria, tais como Wertsch (1988), Baquero (1998), Meira e Lerman (2001), Góes (2000), Góes e Smolka (1997), Colaço (2001) e outros. Estes autores passam, então, a tratar da ZDP como um espaço simbólico de construção que ocorre numa relação dialógica, envolvendo aprendizagens as mais diversas, até mesmo sobre padrões de conduta e processos comunicativos.

Partimos destes pressupostos, portanto, para analisar as estratégias de mediação empreendidas pelas crianças nas situações de interação no contexto de sala de aula, no qual algumas estruturas de papéis sociais são previsíveis, embora as relações que se estabelecem neste ambiente estejam continuamente em movimento e sejam favorecidas pela realização compartilhada de atividades escolares que implicam a criação de novas formas de mediação semiótica entre todos os seus participantes.

Destacamos, outrossim, que, no processo de interação das crianças, ao realizarem as tarefas escolares, não apenas conteúdos específicos são compartilhados, mas também formas de comunicação e conduta, expressão de sentimentos que apontam para a construção de subjetividade na disputa, reprodução e negociação de papéis e valores sociais. 
Desta forma, compreendemos a interação social entre as crianças como processos privilegiados de mediação semiótica, isto porque, para os seres humanos, o desenvolvimento está fundamentalmente governado não apenas por leis biológicas, senão por leis do desenvolvimento cultural, implicadas nas transformações históricas e sociais. Como aponta Werstch (1998), a presença de estímulos criados (signos) junto com estímulos dados é uma característica essencial da psicologia humana. Os signos são ferramentas psicológicas que, analisadas à luz do materialismo histórico-dialético, promovem a construção social da consciência, introduzindo-a num campo simbólico mediado. Por conseguinte, a linguagem é compreendida, não apenas no domínio da língua, mas também no discurso da vida.

É nesse processo de interação social que se constitui a subjetividade, no qual o sujeito, através de mediações intersubjetivas, se apropria da cultura de forma qualitativamente diferenciada dos outros animais, transformando o mundo e a si, numa criativa, singular e compartilhada construção. Como comenta Bakhtin (1992):

O território de cada um de nós não é soberano; ser significa ser para o outro e, por meio do outro, para si próprio. É com o olhar do outro que comunico com meu interior. Tudo que diz respeito a mim chega a minha consciência por meio da palavra do outro, com sua entonação valorativa e emocional. Do mesmo modo que o corpo da criança forma-se no interior do corpo da mãe, a consciência do homem desperta a si própria envolvida pela consciência alheia. (p. 39)

Analisar essas questões remete-nos ao conceito de dialogia, em que Bakhtin (1992) acentua o caráter social e constitutivo da linguagem e a relação intersubjetiva que se estabelece no ato da fala, traduzida na multiplicidade de vozes da vida social e ideológica em diferentes cenários. Dialogia, como processo de interação ativa e de mútua constituição entre os diferentes interlocutores, cujos discursos, no contexto do espaço escolar, evidenciam a presença das múltiplas vozes (polifonia) que os constituem (Brait, 2005).

Apresentamos, até aqui, um panorama dos conceitos e dos processos que serão postos em ação no decorrer do artigo através das análises dos diálogos infantis. Em seguida, explicaremos o caminho metodológico traçado na pesquisa e prosseguiremos discutindo as diferentes estratégias de mediação utilizadas pelas crianças, analisando-as com base nos referenciais teóricos adotados. Num primeiro momento, examinaremos aquelas situações que explicitam construções cognitivas de resolução das tarefas e, depois, nos reportaremos às implicações relativas à construção de subjetividade, à luz da perspectiva dialógica de Bakhtin.

\section{Método}

A abordagem teórico-metodológica do estudo seguiu a perspectiva da pesquisa sócio-cultural (Wertsch et al., 1998) com enfoque etnomentodológico (Coulon, 1995), no que se refere à observação empírica das interações infantis, e microgenético (Góes, 2000), na análise das atividades discursivas das crianças, registradas no decorrer da pesquisa de campo. A proposta de um enfoque etnometodológico caracterizou-se por privilegiarmos a realização de tarefas pelas crianças em situações de interação na sala de aula, nas quais tanto a organização da equipe de crianças como as tarefas propostas eram inseridas no contexto da atividade escolar e apresentadas pelas professoras para todos os alunos da turma, ou seja, focalizamos os modos cotidianos de resolução de tarefas. Trabalhamos com a análise microgenética das atividades discursivas captadas com a gravação em vídeo das interações e dos diálogos infantis.

O locus da investigação foi a sala de aula de duas turmas de quarta série do Ensino Fundamental de uma escola particular de Fortaleza, que prioriza as interações entre alunos em sua didática. As tarefas de resolução de problema apresentadas às crianças nas ocasiões das observações de sala de aula faziam parte do conteúdo escolar e foram elaboradas pelas professoras.

Em cada turma, uma pela manhã e outra à tarde, foram sorteadas pelas respectivas professoras quatro crianças, as quais passaram a compor os grupos que acompanhamos ao longo de um semestre letivo. Portanto, fizemos filmagens das atividades discursivas dos dois grupos de crianças, quando estas realizavam conjuntamente tarefas escolares. Tais filmagens em ambas as turmas tiveram uma freqüência semanal e ocorreram no primeiro semestre de 2004.

No primeiro momento, fizemos uma observação geral em cada turma para conhecer o ambiente e para possibilitar um contato inicial com todas as crianças e, especificamente, com as oito dos dois grupos selecionados.

Toda a equipe de pesquisa trabalhou meticulosamente nas transcrições das filmagens e posteriormente na análise microgenética dessas atividades discursivas dos dois grupos. Transcrevemos cada evento filmado, considerando os diálogos entre as crianças e destas com a professora. Também como integrante do corpus, consideramos os eventos extra-lingüísticos que demarcavam as falas, produzindo assim, no dizer de Bakhtin (1988), diferentes enunciações.

Após as transcrições, passamos à fase de análise, que, como já mencionado, seguiu o modelo da análise microgenética, de modo que incidimos a atenção analítica sobre os diálogos que explicitavam significados e sentidos ${ }^{3}$ construídos pelas crianças em seus momentos de interação. Procuramos, dessa forma, identificar indícios, marcas, que evidenciassem a formação e o uso de estratégias mediacionais para a solução dos problemas envolvidos nas tarefas.

\section{Resultados e discussão}

\section{As estratégias de mediação na resolução de tarefas em sala de aula}

As análises das atividades discursivas das crianças, construídas a partir dos diálogos estabelecidos na realização conjunta das tarefas, dão conta da utilização de diferentes estratégias de mediação, as quais implicam emergência de ZDP, compreendida como espaço simbólico de construção numa relação dialógica que envolve negociação de papéis e, como já frisamos, aprendizagem sobre padrões de conduta e processos comunicativos. Neste sentido, implicam não apenas a construção de novos conhecimentos, como também processos de subjetivação que 
vão se forjando nos espaços de convivência e discussão de sala de aula. Reafirmamos aqui as proposições de Meira e Lerman (2001) de que a emergência de ZDP aparece nas interações e situações comunicacionais, em que estão implicadas "linguagem orientada para o conteúdo" e "linguagem orientada para a comunicação".

Ao tratarmos especificamente das estratégias que foram possíveis de serem identificadas como mediando as atividades discursivas das crianças que protagonizaram a pesquisa, é necessário ressaltar que observamos modos comuns a diferentes tipos de tarefas e também especificidades em relação aos seus conteúdos temáticos. Iremos apontar aquelas que aparecem de maneira geral nas atividades e as que se destacam particularmente nas tarefas de linguagem e nas de matemática.

As estratégias corriqueiramente utilizadas eram de natureza semiótica e possibilitavam o compartilhamento dos conhecimentos envolvidos nas tarefas, na medida em que eram expressas verbalmente pelas crianças ou através de gestos e sinalizações. Ilustramos em seguida alguns excertos dos diálogos das crianças, analisando os elementos que apareceram como mediadores na construção compartilhada. O critério adotado para escolha dos excertos foi a recursividade e representatividade da estratégia, identificada em nossas análises. Assim, destacamos, para efeito de representação empírica, alguns episódios em que apareciam com maior recorrência cada uma das categorias por nós identificadas, a saber: estratégias de uso geral, estratégias usadas especificamente nas tarefas de linguagem e estratégias usadas especificamente nas tarefas de matemática.

Foram identificadas, portanto, como estratégias mais gerais, (independente do conteúdo trabalhado pela atividade): leitura complementar de textos e/ou de enunciados de problemas; repetição de enunciados e frases para melhor compreensão textual ou para explicitação do problema a ser resolvido; complementação e negociação de sentidos e significados; e dicas e pistas verbais para apoiar o/a colega. Destacaremos algumas mais recorrentes.

O primeiro excerto, relativo a estratégias de uso geral, refere-se a uma atividade de linguagem, na qual as crianças deveriam identificar verbos terminados em "am" e em "ão". Demonstramos como a repetição e a complementação auxiliam na construção de sentidos e na resolução da atividade.

Excerto $n^{\circ} 1$ - tarefa de linguagem: verbo (turma da manhã)

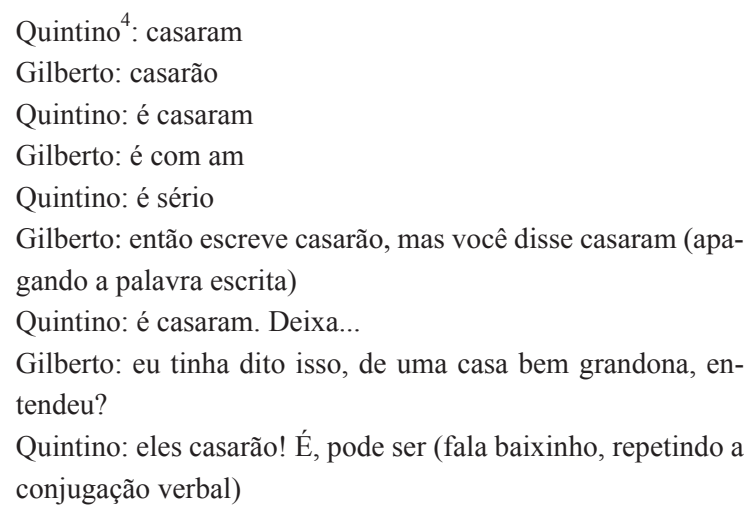

Essa discussão dos dois meninos mostra o uso da repetição da palavra (casaram/casarão) com diferentes entonações enquanto resolvem a tarefa. Ao repetirem, estão também justificando e negociando o significado dado à palavra dita. É interessante perceber como eles vão identificando diferentes significados na própria discussão: casarão como uma "casa bem grandona" e casarão como flexão do verbo casar. Ao conjugá-lo, Quintino se dá conta dessa possibilidade de significado diferente daquele que havia empregado inicialmente, afirmando: “É, pode ser". É possível observar como, de uma discussão inicial sobre ortografia, emerge a possibilidade de novos significados para a palavra em foco. Desse modo, a repetição das palavras auxilia o pensamento e tem uma função importante na resolução da tarefa.

No caso das tarefas de linguagem, consideramos como estratégias específicas os modos de mediação característicos das formas de construir interpretações de textos e de resolver problemas com conteúdo lingüístico. Assim, identificamos nesta categoria: acentuação de palavras ou de conteúdos específicos para dar relevância ao texto; silabação; generalização de conceitos; leitura conjunta e síntese do texto construído. Estas estão também permeadas pelas estratégias de uso geral (repetição, complementação, negociação de significado e sentido, etc.), mencionadas acima.

O excerto dos diálogos abaixo explicita que, ao acentuar palavras ou expressões, a linguagem orienta o pensamento em construção e cria o espaço de negociação que acontece no plano intersubjetivo, possibilitando reconstruções intrapsíquicas. A tarefa consistia na interpretação de estilos narrativos constantes num texto do livro didático.

Excerto $n^{\circ} 2$ - tarefa de linguagem: interpretação de texto (turma da manhã)

Nara: vou colocar um cadáver...

Quintino: (fala ironicamente para Nara). Estilo interjetivo!? Um cadáver? (Repete, dando uma entonação acentuada à expressão). Peraê, raciocina, raciocina comigo: estilo interjetivo. Um cadáver? É, pode ser!

Nara: pode não menino! Tá perguntando aqui... (procura no texto do livro)

Gilberto cantarola.

Nara: (lendo) - Observe que em cada estilo o mesmo quadro é ilustrado de uma forma diferente. Leia o texto e escreva quem ou como.

Quintino: com quem ou com que o narrador está preocupado nos seguintes estilos!? (Explicando para os colegas com um tom bem enfático).

Gilberto: com a pessoa (respondendo).

Quintino: com a pessoa que tá fazendo a história! Que tá fazendo, ô...(corrigindo). Com a pessoa que está na história! (Faz uma expressão facial como se estivesse descobrindo algo). Eu acho que já sei como a gente pode fazer. Sabe como? Pegar um dicionário e ver o que tem em interjetivo. E aqui (referindo-se ao que está indicado no livro), colorido. Estilo colorido: estilo alegre, ê (entusiasmado como se tivesse descoberto a resposta).

A fala de Quintino: "raciocina, raciocina comigo" é um convite à reflexão, inclusive para ele próprio, o que tenta fazer ao repetir enfaticamente a frase da colega e ao complementá-la com a observação do estilo que vinha sendo interpretado pelo 
grupo. Com isso, Nara sente necessidade de retomar a leitura do enunciado da tarefa e é complementada e corrigida por Quintino (“com quem ou com que..."), o que evidencia a construção compartilhada do sentido/interpretação que está sendo buscado. A leitura conjunta e complementada, bem como a ênfase dada a partes do texto, estratégias identificadas neste diálogo travado para interpretar os estilos narrativos, auxiliam na realização do problema. As expressões de entusiasmo de Quintino e sua dedução final "Estilo colorido: estilo alegre, ê", revelam a construção possibilitada pela atividade discursiva (emergência de ZDP), até mesmo demandando o uso de outra ferramenta o dicionário, que auxiliaria na compreensão de um estilo, cujo nome (estilo interjetivo) não favorecia uma dedução imediata do seu significado.

No trecho a seguir, ainda relativo à mesma tarefa, podemos acompanhar um processo de negociação entre as crianças com o intuito de descobrirem qual o significado da palavra "impressionista". Vejamos como as crianças tentam resolver o problema:

Excerto $n^{0} 3$ - tarefa de linguagem: formação de conceitos (turma da manhã)

Nara: Eu botei assim... com a forma que é de colocar o então na frase

Gilberto: Eu coloquei no texto... isso é um texto... que é a forma de colocar o então no texto

Quintino: impressionista...

Nara: Estilo impressionista

Quintino: Eu acho que é impreciosa... sei lá

Gilberto: Não... impressionante... é uma coisa meio impressionante (vira para Nara)... Ah! De colocar um modo que impressione.

Nara: (incompreensível) as pessoas

O grupo, na tentativa de resolução da tarefa - interpretar os estilos narrativos - se deparou com a necessidade de descobrir qual o significado da palavra impressionista. Diante dessa dificuldade, as crianças lançam mão de buscar em outras palavras conhecidas - e que possuem a mesma raiz - o significado de "impressionista", para daí entender o que seria um estilo impressionista. A estratégia aqui é a mesma de que Vygotsky (1934/1993) nos fala quando discute o processo de formação de conceitos, ou seja, o sujeito constrói o significado das novas palavras a partir do significado de palavras que já conhece. Neste caso, identificamos o modo utilizado como uma estratégia de generalização de conceitos. Há uma negociação do significado da palavra por meio de critérios de aproximação lingüística: impressionante, impressione, impressionista. A estratégia foi utilizada de modo compartilhado por Quintino, Gilberto e Nara para chegarem a uma solução conjunta do problema. A complementação feita por Nara da fala de Gilberto nos sugere que ela estava acompanhando o raciocínio dele e que, portanto, compreendeu o uso da sua estratégia de mediação, o que foi evidenciado um pouco mais adiante, quando ela sintetiza a discussão e a complementa, introduzindo sua própria interpretação:

Nara: Ele está preocupado com... eu vou botar atrair pessoas... impressionar as pessoas.

Esta fala nos mostra o resultado do processo de construção de significados e sentidos compartilhados. Ela agrega tanto os resultados do uso da estratégia de buscar o novo significado da palavra desconhecida através de outras conhecidas e/ou de mesma raiz lingüística (generalização de conceitos), como da indicação da interpretação do texto, que era o problema principal da tarefa. Ou seja: se a frase do texto apresentava um "estilo impressionista", aquela deveria ter como objetivo "atrair pessoas... impressionar as pessoas".

Como dissemos antes, nos debruçamos também nas estratégias utilizadas na resolução de problemas matemáticos. Neste caso, também estão presentes a repetição e a complementaridade, mas somam-se a elas outras estratégias específicas da natureza da tarefa em discussão - atividades de conteúdo numérico. São elas: demonstração da contagem numérica e de suas representações (uso dos dedos, batidas na mesa, riscos no papel, continhas parciais, etc.); síntese do problema em questão como forma de revisão e correção da tarefa; negociação de modos variados de representação do problema. Procuraremos ilustrar algumas dessas estratégias que apareceram com maior evidência.

Em uma dada oportunidade, as crianças deveriam elaborar uma expressão numérica para, posteriormente, passá-la a outro grupo de colegas para que a resolvessem. Essa atividade requeria muita atenção das crianças nas diversas partes da expressão, pois era imprescindível a observação à regra da hierarquia dos agrupadores (parênteses, colchetes e chaves) e das operações matemáticas básicas envolvidas. Durante a elaboração da expressão numérica, um dos membros do grupo preocupava-se em fazer a revisão e correção da expressão de modo a refazer o caminho daquele que estava resolvendo a tarefa.

Percebemos como as crianças negociavam formas de construir a expressão matemática. Uma primeira maneira de elaborar a expressão foi sugerida por uma das crianças - Artur - que propunha usar um valor arbitrário como resposta à possível expressão e, a partir daí, tentava elaborar a expressão numérica para chegar àquele valor estabelecido inicialmente. Ou seja, o método usado por ele era partir de um resultado pré-definido para daí formular a expressão numérica. A segunda forma foi proposta por outra criança - André - ao perceber a dificuldade da primeira. Neste caso, as crianças passaram ao encadeamento da expressão sem um resultado pré-estabelecido, embora a criança que propôs esse modo de construção da expressão matemática estivesse preocupada com a existência de um resultado possível, ou seja, nos dois procedimentos, estava presente a intenção de resolutibilidade do problema, pois este deveria ser resolvido por outro grupo de alunos.

Excerto $n^{0} 4$ - tarefa de matemática (turma da tarde)

Ana Patrícia: Mas esse é um número difícil (o colega havia indicado um número como resultado da expressão).

Artur: Dividido. Vai dar o quê? Tem que saber o que é que dá, para vê/

Ana Patrícia: sete e sete são catorze.

Arthur: Não Ana Patrícia, é 212 mais/

Ana Patrícia: Perainda, peraí. Como Artur?

Artur: Não, então não apaga não. Dividido aqui. Parêntese. Abre parêntese. Agora todo mundo... Calma que eu ainda vou coisar. 897 (fala baixinho) (incompreensível) menos 99. 
Ana Patrícia: Não, mas soma logo esse 97 para diminuir. Artur: 97, 98, 99, 100, 101, 102, 103, 104 (contando nos dedos).

Ana Patrícia: menos 104.

Artur: 104. Aqui o número (incompreensível). (Artur faz uns cálculos num papel à parte, silenciosamente). Dá nove, 995 . Ana Patrícia: Não consigo dividir por/ (olha para Arthur). André observava os dois trabalhando.

Era possível perceber que Artur, que havia proposto iniciar com um resultado pré-definido, expressava seu raciocínio usando formas de representação parciais dos cálculos que ia realizando (estratégias de contagem nos dedos, repetição oral dessa contagem e realização de pequenas contas). Enquanto ele fazia e oralizava seus cálculos, Ana Patrícia e André acompanhavam suas elaborações. Continuando na mesma tarefa, vejamos a proposta de André para mudança do caminho de construção da expressão numérica.

Excerto $n^{0} 5$ - tarefa de matemática (turma da tarde)

Artur: Então calma, dá 995 dividido por... Dá 995 dividido/

André: Calma aí. Posso dar essa idéia?

Artur: Peraí. Dá 995 divido por três. Bote aí.

André: Seria bem melhor colocar um número, por exemplo, 89 mais trinta e três/ (propondo ir construindo o problema paulatinamente)

Ana Patrícia: menos três

Artur: 33 mais 33 dá 66 (Ana Patrícia e Artur escrevem).

Ana Patrícia: Nada Artur. Nada.

Artur: Peraí. Nada também, porque 33 vezes três dá 99. Quer vê? Ó (faz a conta no papel). 33 vezes três. Três vezes três, aí, calma, aí três vezes três, nove, dá 99 .

Ana Patrícia: Por nada... (os dois estão fazendo os cálculos no papel)

Artur: Vai cinco. Dá um. Esse aí abre chave. Então a gente/

André: Por que a gente não coloca cinco vezes.

Ana Patrícia: Peraí.

Artur: Porque (incompreensível).

André: Perainda. 89 mais oito. Aí vem pra cá 97, 97 dividido por

97 dá um, que é exato. (Indicando uma resposta adequada)

Artur: Então coloca aí.

Ana Patrícia: É, noventa e quatro? (Para André).

André: O quê?

Ana Patrícia: Aqui (mostrando a folha).

André: Nove, sete.

Ana Patrícia: Aqui é 97 André? É?

André: (Olha na folha) Isso aqui é?

Ana Patrícia: É aqui? Oito, né?

André: Aqui é sete.

Ana Patrícia: Sim e aqui, agora?

André: Aqui no parêntese que eu colocaria. Era 89 mais oito (outro colega o interrompe)

Ana Patrícia: Sim, vai 89 mais oito.

André: Aí fecha parêntese.

Artur: Aí fecha parêntese

André: O resto fica com ele (para Artur).

Artur; O resto... vai, acabou de fechar colchete, fechar chave e igual. Pronto já acabou.
Ana Patrícia: Terminamos tia.

Este excerto é ilustrativo do modo como as crianças vão construindo conjuntamente o problema, de modo que o grupo procurou se ajudar, e aqueles que demonstravam mais habilidade na resolução da tarefa indicavam o meio de resolução do problema. À medida que Artur e André negociavam formas de resolução da tarefa, Ana Patrícia acompanhava o raciocínio e também avançava na compreensão do problema.

Mesmo que algumas crianças não possuam domínio completo das operações matemáticas, no momento da realização conjunta da tarefa, o problema vai sendo resolvido e novas possibilidades de solução são coletivamente utilizadas e apropriadas como conseqüência da mediação simbólica dos companheiros mais competentes.

Isto nos conduz à observação de Vygotsky (1928/2001) acerca do valor construtivo da ZDP:

o psicólogo [também se poderia afirmar sobre o professor], ao valorizar o estado de desenvolvimento, deve ter obrigatoriamente em conta não só as funções maduras, mas também aquelas que estão em vias de maturação. Não só o nível atual, mas também a Zona de Desenvolvimento Proximal. (p. 238)

Ou seja, as interações em sala aula dão conta de uma rica possibilidade para o favorecimento da maturação de funções ainda em vias de desenvolvimento, ampliando cada vez mais o estado de desenvolvimento atual, potencializando-o para o futuro.

Também para ilustrar estas estratégias específicas de tarefas de matemática apresentaremos um excerto dos diálogos das crianças, focalizando uma situação em que elas trabalhavam com um recurso didático denominado Material Dourado. Este material é composto por blocos de madeira em forma de cubos pequenos (representando unidades do sistema decimal), barras compridas (representando dezenas), blocos quadrados (representando centenas) e cubo grande (representando milhar).

Na situação em pauta, três das crianças sabiam lidar muito bem com esse recurso didático, mas uma delas (Marina) estava iniciando o contato com o material e não conhecia as equivalências entre as peças. As três crianças foram requisitadas pela professora a orientar a colega. A tarefa envolvia alguns problemas aritméticos com as operações básicas de somar e subtrair. Eles inicialmente faziam o problema sem muita preocupação em explicar para a colega, mas ao questionarem se ela havia entendido, ela balança a cabeça negativamente. Neste momento, Artur e Ana Patrícia buscam formas (estratégias) para que a colega consiga compreender as equivalências entre as peças do Material Dourado. Observemos como eles organizam de forma compartilhada essas estratégias.

Excerto $n^{0} 6$ - tarefa de Matemática (turma da tarde)

Artur: não é dez, negativo isso aí. É dez mil. Ah (olhando para Marina). Primeiro a gente vai somar nove mais oito (mostrando à colega separadamente os nove cubos e os oito cubos pequenos representantes das unidades) que dá: $1,2,3,4,5,6,7,8,9,10$, $11,12,13,14,15,16,17$ (apontando cada um deles enquanto fazia a soma). Dezessete ai. Isso aqui são 10 coisinhas desse (comparando dez cubos pequenos com um bloco representativo 
das dezenas). Então, eu já tenho 10 coisinhas desses (coloca cada pecinha de unidade em cima da barra de dezena para mostrar a Marina a relação entre os dois tipos de peças e vai contando oralmente). Um, 2, 3, 4, 5, 6, 7, 8, 9, 10. Aí eu já posso transformar!

Ana Patrícia: essa coisa tem dez bichinhos desses (explicando a Marina o que o colega havia feito e mostrando o bloco da dezena e também comparando com os cubinhos das unidades. Em seguida retira os dez cubinhos de cena).

Quando Artur termina de contar os outros sete que restavam, procura e não acha os cubinhos que foram retirados por Ana Patrícia.

Artur: Ana Patrícia, que foi que tu fez? Ã, ã, ã?

Ana Patrícia: eu tirei daqui ó. (Mostra a ele onde havia colocado).

Artur: isso aqui é daqui, Ana Patrícia. Se eu tava/

Ana Patrícia: não, mais tu já coisou (indicando que a transformação já havia sido feita).

Artur: aí se transforma nisso (mostrando a barra de dezena para Marina). Sobrou isso (os sete cubinhos). Isso aqui (mostrando novamente as unidades restantes) não dá para se transformar de novo nisso aqui (mostrando a dezena). Então, isso aqui já é o resultado das duas coisas que a gente fez aqui. (separa as unidades) Entendeu? (dirigindo-se à Marina, que estava atenta a toda a operação realizada pelos dois colegas).

Marina balança a cabeça positivamente, desta vez mais convencida com a explicação.

Fica evidente neste excerto a intenção deliberada das duas crianças (Artur e Ana Patrícia) em explicar o uso do Material Dourado para a colega, ao mesmo tempo em que resolviam o problema apresentado pela professora para toda a turma. Em suas explicações, eles passam a usar estratégias claras de demonstração acerca da representação numérica que estavam utilizando. Era necessário explicar a equivalência entre as peças para a colega e também seguir com a resolução do problema. Assim, utilizavam-se das peças para resolver os cálculos colocados na lousa pela professora e ao mesmo tempo para demonstrar à Marina as transformações feitas (de 10 unidades para uma dezena e assim sucessivamente). Para tanto, gesticulavam com os dedos, indicando as quantidades, e também colocavam as peças de um tipo em cima da peça equivalente, num processo de demonstração. A linguagem acompanha todo o procedimento, com enunciados que vão da contagem oral à repetição e à síntese do processo, por exemplo: "Então, isso aqui é o resultado das duas coisas que a gente fez aqui".

Mais uma vez, ressaltamos como as situações de interação entre as crianças possibilitam que aquelas que possuem habilidade na resolução de tarefas apóiem aquelas que têm alguma dificuldade para tal. "As situações de interação social assumem papel decisivo, pois são concebidas como espaço simbólico gerador de conhecimentos, de apropriação de significados e de construção de subjetividades, por conseguinte, promotoras de aprendizagens que impulsionam o desenvolvimento" (Colaço et al., 2004, p. 4).

$\mathrm{Na}$ sala de aula, tanto havia o auxilio da professora como em diversos momentos o grupo se articulava e, de acordo com os papéis ali estabelecidos, os companheiros mais competentes ${ }^{5}$ auxiliavam os demais na elaboração da atividade. A interferência do adulto (professora) era condição capital para a resolução das tarefas escolares. Todavia, também dentro do próprio grupo de crianças essa situação acontecia. A solução da tarefa se dava pelo auxílio de um ou mais companheiros mais competentes, que, através de sua intervenção mediacional, promovia a organização dos membros do grupo, auxiliando-os na resolução do problema.

\section{A mediação simbólica e a construção de subjetivida- de no contexto de sala de aula}

O espaço de sala de aula, enquanto lugar de trocas e interações sociais, assim como outros ambientes humanos, veicula, constrói e reconstrói conhecimentos e significados que implicam aprendizagens de conteúdos conceituais e também aprendizagens de formas de convivência, de comunicação e de papéis sociais. Neste sentido, é um lugar de novas construções inter e intrasubjetivas, em que os atores sociais que dele participam (professores, professoras, alunos, alunas e outras pessoas que nele se insiram, como por exemplo, agentes de pesquisa) compartilham modos de compreender o mundo e atitudes frente a este.

Ou seja, a sala de aula é um ambiente de relações dialógicas que envolve negociação de papéis, aprendizagem sobre padrões de conduta e processos comunicativos, além dos conteúdos curriculares que movem os objetivos explícitos deste contexto. Isto implica, portanto, não apenas a construção de novos conhecimentos, mas processos de subjetivação que nele vão se forjando.

No decorrer das interações das crianças para a realização das tarefas escolares, evidenciamos esse processo construtivo em curso. Da mesma forma que em estudo anterior (Colaço, 2004), pudemos observar que ao orientarem os colegas, algumas crianças legitimavam o seu saber e assumiam papéis específicos, cujo modo de agir e de falar se assemelhava às intervenções da professora. Por vezes, uma criança se colocava como líder numa determinada atividade, mas essa liderança também circulava entre outras crianças do grupo, o que indica que esses papéis não são fixos, mas negociados. No entanto, estão vinculados ao modo como cada um se apresenta no domínio da atividade específica e na relação que estabelece com as outras crianças (Tudge, 1996). Assim sendo, ora uma criança colocava para si, legitimada pelas demais, a função de ensinar a tarefa para as outras, ora a mesma criança aparecia como a que registrava ou assumia a função de organizar a tarefa (definir quem faz o que) ou de conciliar modos diferentes de resolução de problemas. Este jogo de papéis configura interações que vão indicando atitudes e gêneros discursivos particulares (Bakhtin, 1992; Barros, 1999). A postura de uma criança ensinando ao colega, por exemplo, é geralmente acompanhada de um modo discursivo que se assemelha ao do professor. Esta formação discursiva leva a criança a se assumir como competente, isto é, no processo comunicativo as crianças se reconhecem e assumem papéis, portanto, se constituem subjetivamente.

Apresentamos um excerto dos diálogos que ilustra esse jogo de papéis e sua aceitação tácita entre as crianças em sala de aula. Trata-se de uma das tarefas ilustradas anteriormente em que as crianças deveriam elaborar expressões matemáticas para serem 
resolvidas por outras equipes, expressões estas que envolviam o uso dos agrupadores: chave, colchete e parênteses.

Excerto $n^{\underline{0}} 7$ - tarefa de Matemática (turma da tarde)

André: Quem vai fazer a segunda?

Ana Patrícia: Eu.

André: Mas é bom cada um fazer uma.

Artur: Olha como tá (passa o papel para André).

André (Lê o problema) Quinze menos. Abre chave. Quatro mais seis, dividido por dezoito. Abre colchete. Vinte e quatro menos vinte e dois. Abre parênteses. Quarenta e oito vezes trinta e dois. Fecha parênteses e fecha colchete.

Ana Patrícia: Pronto, tá bom? (perguntando a André)

Marina pega o papel para ver a expressão.

A professora se aproxima e pergunta se está tudo ok.

Ana Patrícia: Tudo, mas a gente ainda vai fazer a segunda.

Profa: Certo!

Ana Patrícia (para André): Vai, diz!

André: Agora. Cento e trinta e dois (faz um gesto indicando o dois com os dedos).

Ana Patrícia: Cento e trinta e dois.

Artur: Ainda bem que (incompreensível).

Ana Patrícia: Vai, vai

André: Multiplicado

Ana Patrícia: Multiplicado

André: Abre chaves

Ana Patrícia: Chave?

André: Ahã, ahã.

Neste trecho do diálogo, é possível perceber a posição de liderança ocupada por André, que fazia apontamentos acerca da necessidade de cada um do grupo fazer uma questão. Os papéis desempenhados pelos membros do grupo na tarefa estavam bem delimitados e a forma com que cada um os assumia era fator de legitimação do seu modo de interagir com os demais, que aceitavam e se comportavam de acordo com esses parâmetros estabelecidos entre eles. Assim, André, que já havia demonstrado o entendimento da tarefa ao propor o problema anterior, lidera a atividade, enquanto os demais seguem sua orientação. Ele apresenta toda a expressão matemática e Ana Patrícia a copia e acompanha o seu raciocínio, pedindo a confirmação do que vai escrevendo.

Algumas crianças assumem o comando da atividade com maior freqüência, outras participam de forma menos ativa, entretanto, essas posições não são fixas e dependem das conquistas que cada uma vai adquirindo nas interações, de seus diferentes modos de participação e do maior ou menor domínio que demonstram na tarefa específica. Isto significa que, na realização da atividade, as crianças se constituem como sujeitos, uma vez que representam papéis sociais, estabelecem formas de comunicação, expressam sentimentos, reagem às ações do outro etc.

Os processos e estratégias de mediação implicados na construção do conhecimento escolar que abordamos acima são, portanto, perpassados por valores, sentimentos e expressão de significados culturalmente construídos e, neste caso específico da sala de aula, refletem o ambiente escolar com suas características discursivas próprias e com sua especificidade de atividades.

Seguindo o pensamento de Vygotsky e de Bakhtin e de seus desdobramentos posteriores, particularmente, nos trabalhos de Wertsch (1998) e Wertsch et al. (1998), compreendemos que o processo de subjetivação se realiza pela e na ação mediada, o que caracteriza a atividade humana. Nesta mesma perspectiva, Zanella (2004) indica como característica da atividade humana

o fato de esta [atividade humana] produzir cultura e consistir em objetivação do sujeito que a empreende. Porém, esse processo de objetivação pressupõe ao mesmo tempo a subjetivação do sujeito, pois, ao apropriar-se da atividade, o sujeito apropria-se da história humana e imprime a esta sua marca. (p. 132)

\section{Considerações finais}

A partir das análises aqui empreendidas, podemos fazer algumas reflexões acerca do papel potencializador das interações das crianças em sala de aula. A riqueza percebida nessas interações deixa-nos clara a força construtiva dos processos mediacionais, estando estes circulando a todo o momento nas relações sociais estabelecidas no contexto escolar.

Seguindo a trilha dos autores que referenciaram teoricamente a pesquisa, as observações do cotidiano da sala de aula revelaram o papel da linguagem como organizadora do pensamento, como integradora das ações e como recurso privilegiado de mediações, que por meio de redes de significações construídas na intersubjetividade promovem as reconstruções singulares de cada sujeito, tanto no que se refere aos conhecimentos novos daí originados, como na produção de suas subjetividades, forjadas nessas interações.

Creditamos importância fundamental também ao encaminhamento didático do professor, que pode proporcionar e acompanhar espaços de convivência e intercâmbios no interior da sala de aula, estimulando a expressão discente e o trabalho em equipe.

No ambiente escolar, situações didáticas que favorecem o intercâmbio entre as crianças e destas com o professor são ricos espaços de discussão que geram uma contínua construção de mediadores semióticos envolvidos na realização de tarefas. Tanto professores como alunos participam desse processo, criando estratégias que melhor viabilizam a resolução de problemas. Isto implica situações de aprendizagens para ambos. O que buscamos tematizar com os diálogos foi a compreensão dos espaços de trocas gerados em sala de aula, os quais revelam condições de construção de conhecimento e, por conseguinte, emergência de ZDP. Isto significa compreender o conceito de zona de desenvolvimento proximal como um espaço simbólico de construção, o que implica uma análise das configurações interacionais que envolvem contextos de aprendizagem.

Consideramos que investigações dessa natureza podem originar uma conscientização maior dos potenciais de aprendizagem que circulam no ambiente escolar. A valorização dos recursos e estratégias didáticas, da construção coletiva entre alunos e professores e o reconhecimento do papel organizador e mediador da linguagem, são elementos fundamentais para se repensar as práticas pedagógicas e o papel do docente.

Por fim, quisemos também mostrar que o enfoque históricocultural possibilita o reconhecimento das complexidades e nuan- 
ces do fazer pesquisa com um olhar dialógico sobre o material empírico, e permite valorizar alterações que surgem no decorrer das análises, as quais favorecem reconstruções de objetivos e reconfigurações no desenho da pesquisa.

\section{Agradecimentos}

Os autores agradecem o apoio financeiro proporcionado por Universidade Federal do Ceará (bolsa PIBIC/UFC), SESu/MEC (bolsa PET-Psicologia/UFC) e Fundação Cearense de Apoio à Pesquisa (FUNCAP).

\section{Referências}

Bakhtin, M. (1988). Marxismo e filosofia da linguagem. São Paulo: Hucitec. Bakhtin, M. (1992). Estética da criação verbal. São Paulo: Martins Fontes. Barros, D. L. P. (1999). Dialogismo, polifonia e enunciação. In D. L. P. Barros \& J. L. Fiori (Orgs.), Dialogismo, polifonia e intertextualidade (pp. 1-9). São Paulo: EDUSP.

Baquero, R. (1998). Vygotsky e a aprendizagem escolar. Porto Alegre: Artes Médicas.

Brait, B. (Org). (2005). Bakhtin: conceitos-chave. São Paulo: Contexto.

Colaço, V. F. R. (2001). Interações em sala de aula: um estudo da atividade discursiva de crianças em séries iniciais. Tese de Doutorado não-publicada, Universidade Federal do Rio Grande do Sul, Porto Alegre.

Colaço, V. F. R. (2004). Processos interacionais e a construção de conhecimento e subjetividade de crianças. Psicologia: Reflexão e Crítica, 17(3), 333-340.

Colaço, V. F. R., Mota, M. L. A., Chaves, H. V., Pereira, E., \& Sá, T. S. (2004). Estratégias de mediação em situações de interação infantil e seu papel na construção de conhecimento e subjetividade. Relatório de pesquisa não- publicado, Universidade Federal do Ceará, Fortaleza.

Coll, C., \& Onrubia, J. (1998). A construção de significados compartilhados em sala de aula: atividade conjunta e dispositivos semióticos no controle e no acompanhamento mútuo entre professor e alunos. In C. Coll \& D. Edwards (Orgs.), Ensino, aprendizagem e discurso em sala de aula: aproximações ao estudo do discurso educacional (pp.75-106). Porto Alegre: ArtMed.

Coulon, A. (1995). Etnometodologia e Educação. Petrópolis: Vozes.

Góes, M. C. R. (2000). A abordagem microgenética na matriz histórico-cultural: uma perspectiva para o estudo da constituição da subjetividade. Caderno CEDES, 20(50), 9-25.

Góes, M. C. R., \& Smolka, A. L. B. (Orgs.). (1997). A significação nos espaços educacionais: interação social e subjetivação. Campinas: Papirus.

Leontiev, A. N. (1978). O desenvolvimento do psiquismo. Lisboa: Livros Horizonte.

Meira, L., \& Lerman, S. (2001). The zone of proximal development as a symbolic space. Social Science Research Papers, 1(13), 1-40.

Tudge, J. (1996). Vygotsky, a zona de desenvolvimento proximal e a colaboração entre pares: implicações pedagógicas para a prática em sala de aula. In L. C. Moll (Org.), Vygotsky e a educação: implicações pedagógicas da psicologia sócio-histórica (pp. 187-207). Porto Alegre: Artes Médicas.

Vygotski, L. S. (1993). Pensamiento y lenguaje. In Obras Escogidas (pp. 9-348). Madrid: Visor. (Texto original publicado em 1934)

Vygotsky, L. S. (2001). Psicologia pedagógica. São Paulo: Martins Fontes. (Texto original publicado em 1928)

Wertsch, J. (1988). Vygotsky y la formación social de la mente. Barcelona: Paidós.

Wertsch, J. (1998). La mente em acción. Madrid: Aique.

Wertsch, J., Del Rio, P., \& Alvarez, A. (1998). Estudos socioculturais da mente. Porto Alegre: Artes Médicas.

Zanella, A. V. (2004). Atividade, significação e constituição do sujeito: considerações à luz da Psicologia Histórico-Cultural. Psicologia em Estudo, $9(1), 127-135$.

${ }^{1}$ A concepção de atividade é mais abrangente do que a idéia de ação, isto porque, tanto para Leontiev (1978), que empreende toda uma teorização acerca da atividade como construtora do psiquismo humano, como para Vygotsky, que insistiu na idéia de que a atividade humana é social e, portanto, mediatizada por instrumentos e signos. O que caracteriza a diferença entre atividade e ação é o fato de que na primeira está sempre implicado um processo de significação, construído socialmente e compartilhado numa dada cultura. A ação é parte da atividade, mas esta não se encerra nela.

${ }^{2}$ É necessário explicitar que o conceito de subjetividade que está sendo tematizado neste texto vincula-se às concepções vygotskiana e bakhtiniana, as quais abordam o sujeito construído na sua relação com o outro, mediada pela linguagem. Trata-se, portanto, de uma compreensão histórico-cultural da noção de subjetividade, processo em permanente construção nas interações cotidianas e forjado pela inserção do sujeito em uma determinada cultura.

${ }^{3}$ Estamos considerando a distinção feita por Vygotsky (1934/1993) quando trata de significado e sentido. O primeiro, referindo-se ao elemento denotativo da palavra, ou melhor, o significado compartilhado coletivamente e convencionalmente atribuído a ela em cada língua. Já o sentido aponta para a singularidade do processo de significação em que cada pessoa atribui valor conotativo às palavras a partir de suas próprias experiências e interações.

${ }^{4}$ Todos os nomes das crianças referidos neste relatório são fictícios e visam a preservar o sigilo e a ética da pesquisa.

${ }^{5} \mathrm{O}$ que estamos chamando de maior competência, neste caso, se refere a uma habilidade maior na situação ou tarefa específica e não a uma competência generalizada do desempenho escolar de uma ou mais crianças em relação às demais do grupo. 
Veriana de Fátima Rodrigues Colaço, doutora em Educação pela Universidade Federal do Rio Grande do Sul, é Professora Adjunta na Universidade Federal do Ceará. Endereço para correspondência: Departamento de Psicologia, Av. da Universidade, 2762 (Benfica); Fortaleza, CE; CEP 60020-180. Tel.: (85) 3366-7723. Fax: (85) 3366-7727. E-mail: verianac@uol com.br

Eleonora Pereira, graduada em Psicologia pela Universidade Federal do Ceará, é psicóloga no Hospital Universitário Walter Cantídio.

Francisco Edmar Pereira Neto é mestre em Psicologia pela Universidade Federal de Pernambuco.

Hamilton Viana Chaves, mestre em Psicologia pela Universidade Federal do Ceará, é professor na Universidade de Fortaleza (UNIFOR) e psicólogo no Centro Federal de Educação Tecnológica do Ceará (CEFET/ $\mathrm{CE})$.

Ticiana Santiago de Sá, graduada em psicologia pela Universidade Federal do Ceará, é psicóloga na Fundação da Criança e da Família Cidadã (FUNCI). 